\title{
Melt Infiltration Casting of Alumina Silicon Carbide and Boron Carbide Reinforced Aluminum Matrix Composites
}

\author{
Ali Kalkanlı*, Tayfun Durmaz ${ }^{1}$, Ayşe Kalemtaş ${ }^{2}$ and Gursoy Arslan ${ }^{3}$ \\ ${ }^{1}$ Department of Metallurgical and Materials Engineering, Middle East Technical University, Ankara, Turkey \\ ${ }^{2}$ Department of Metallurgical and Materials Engineering, Bursa Technical University, Turkey \\ ${ }^{3}$ Materials Science and Engineering, Anadolu University, Eskişehir, Turkey
}

\begin{abstract}
This paper discuss the effect of processing details such as particle size, sintering temperature, preform preparation, aluminum alloy characteristics and melt temperature on the final mechanical properties of ceramic phase reinforced metal matrix composites. Since alloy composition was determined as 7075 and 7085 optimum solutionizing and ageing temperatures were studied to determine maximum hardness values. For only 7085 alloy best solutionizing temperature is $465^{\circ} \mathrm{C}$ and for 7075 alloy the maximum hardness achived as $178 \mathrm{BHN}$ after heat treatment at $475^{\circ} \mathrm{C}$. Alloys were heat treated for recystallization after hot rolling grain size were measured as $100-120 \mu \mathrm{m}$ for 7085 alloy matrix.

Various sintering temperatures were used for preform preparation such as $1300-1450^{\circ} \mathrm{C}$. In $85 \% \mathrm{Al}_{2} \mathrm{O}_{3}$ reinforced 7085 Alloy based MMCs preforms sintered at $1450^{\circ} \mathrm{C}$ high hardness values were achieved as $545 \mathrm{BHN}$. Intermetallic phase was determined in 7075 and 7085 alloys selected as alloy matrix. $\mathrm{Al}_{2} \mathrm{Cu}$ intermetallic pecipitate $(\theta$ phase) was determined as dominant second phase after T6 heat treatment but highly expected phase in 7000 series alloys $\mathrm{MgZn}_{2}$ ( $\eta$ phase) was not determined by XRD and SEM analysis techniques due to ultrafine precipitate size and homogeneous distribution.
\end{abstract}

Keywords: Composite materials; Armor materials; Ductility

\section{Introduction}

Development of metal ceramic composite materials with possible lowest density and higher energy absorbing capacity is highly important issue for defense industry. So, many criteria's should be considered when selecting of materials that are used in armor system. The impact resistance of shield materials against projectile is strongly required to be determined.

Scientific research on metal matrix composites and mechanical characterization by three point bending, hardness and impact toughness measurements are typical tests for performance characterization apart from ballistic tests.

Boron carbide is known with its extreme hardness of $30 \mathrm{GPa}$. It is the hardest third material after diamond and cubic-BN which are very expensive and hard to prepare. At temperatures above $1200^{\circ} \mathrm{C}$ its hardness value even exceeds that of diamond [1]. Combination of high hardness and low density makes boron carbide top candidate of armor materials. However low strength, high price, poor fracture toughness, sinterability and machinability of boron carbide limits its industrial applications [2]. Also, boron carbide doesn't provide efficient protection to stop armor piercing bullet with high velocity due to amorphisation process that occurs in boron carbide in the presence of high pressure. At this pressure, ballistic performance of boron carbide drops because shear strength of boron carbide decreases. Another problem with boron carbide is its brittleness which makes them not suitable for multi-hit protection [3]. The popularity of silicon carbide for armor technologies has increased due to its improved cost/performance ratio relative to other candidate materials like alumina [4]. Silicon carbide is produced in larger scales because it has many fields of application areas compared with boron carbide. The price of silicon carbide is lower than that of boron carbide and ballistic performance of silicon carbide is very close to that of boron carbide. Thus many researchers have worked for production of armor system with as low boron carbide content as possible [5]. Silicon carbide is often mixed with boron carbide, but monolithic silicon carbide is also used in production of armor materials. Density of silicon carbide is $3.21 \mathrm{~g} / \mathrm{cm}^{3}$ which are between that of boron carbide and alumina. Hardness of silicon carbide is very close to that of boron carbide. Thus for higher level ballistic threats silicon carbide is better alternative than boron carbide in spite of its higher density [3].

Although ceramic armors are used currently, low fracture toughness and high expense of them limits their widespread use. They do not provide efficient protection against multi-hit in a short space of time. After the first hit, armor system is expected to heavily damage and then any bullet would penetrate armor system which have already fractured [6]. Combining ceramic materials with a metal may provide better ballistic efficiency. So creating of porous ceramic preform, then infiltrating it with a ductile metal is considered as solution. Aluminum is most widely used infiltrated metal because of its low density, low melting point and outstanding ductility. It is also non-toxic, relatively inexpensive and easy to obtain. Molten aluminum reacts with boron

${ }^{*}$ Corresponding author: Ali Kalkanli, Department of Metallurgical and Materials Engineering, Middle East Technical University, Ankara, Turkey, Tel: +90 (312) 2105929; E-mail: kalkanli@metu.edu.tr

Received July 07, 2017; Accepted July 20, 2017; Published July 30, 2017

Citation: Kalkanlı A, Durmaz T, Kalemtaş A, Arslan G (2017) Melt Infiltration Casting of Alumina Silicon Carbide and Boron Carbide Reinforced Aluminum Matrix Composites. J Material Sci Eng 6: 357. doi: 10.4172/2169-0022.1000357

Copyright: $\odot 2017$ Kalkanlı A, et al. This is an open-access article distributed under the terms of the Creative Commons Attribution License, which permits unrestricted use, distribution, and reproduction in any medium, provided the original author and source are credited. 
carbide easily, thus infiltration process may be achieved. Resulted $\mathrm{B}_{4} \mathrm{C}$ $\mathrm{SiC}-\mathrm{Al}_{2} \mathrm{O}_{3}-\mathrm{Al}$ composites exhibit combination of high hardness and high toughness without defeating the aim of obtaining lightweight structure [7]. It is very hard to obtain $100 \%$ dense $\mathrm{B}_{4} \mathrm{C}-\mathrm{SiC}-\mathrm{Al}_{2} \mathrm{O}_{3}$ composites due to presence of strong covalent bonds, high resistance to grain boundary sliding and absence of plasticity which limit their diffusion coefficients in sintering process. Combination of high temperatures and high pressures used in sintering process is the most important economic problem besides the high cost of powders [7] Compared with traditional sintering techniques, melt infiltration is a promising process to produce composite with porous ceramic preforms due to its several advantages. Near or near-net shape composites with high volume fraction ceramics can be obtained. And these ceramic phases can be uniformly distributed in composite structure. Resulted composite exhibits high dimensional stability [8]. Residual stress build up due to different thermal expansion of dissimilar materials can be eliminated, thus residual porosities are prevented. Mechanical properties of composite can be arranged via addition of appropriate compounds or elements [9]. Using high strength aluminum alloy such as 7075 as matrix alloy with addition of $\% 10 \mathrm{SiC}$ displays high flexure strength values $600 \mathrm{MPa}$ reported [9]. Reaction products and reaction rate between ceramic and metal phases can be controlled. The most important advantage of pressureless melt infiltration is that there is no need to use high temperatures and high pressures (when wetting condition is provided there is no need to apply pressure-pressureless melts infiltration) that makes this process very economic. The most important criteria of melt infiltration process are the wetting behavior of the system. Wettability is the ability of a liquid to spread on a solid surface and it demonstrates the extent of close contact between a liquid and a solid [5]. The driving force for wetting is the reduction in free energy of the system. Wetting of the ceramic phase by the metal must be achieved for infiltration process because in the absence of wetting there is no interfacial reaction between ceramic and metal phases [10]. With appropriate temperature and atmosphere conditions, wettability between ceramic and metal phases is achieved and liquid metal is drawn into the porous ceramic preform via capillarity thermodynamic criteria [9] (Table 1).

Lee and Hong worked on production of high volume fraction $\mathrm{SiC} /$ Al metal matrix composites by pressure infiltration method. High volume fraction of metal matrix composites such as $\mathrm{SiC} / \mathrm{Al}$ composites containing nearly $70 \mathrm{vol} \% \mathrm{SiC}$ particles could be fabricated without forming residual porosity and $\mathrm{Al}$ vein layers by pressure infiltration method controlling such process parameters for $\mathrm{Al}$ melt temperature $800^{\circ} \mathrm{C}, \mathrm{SiC}$ preform preheat temperature $550^{\circ} \mathrm{C}$, infiltration pressure 30-50 MPa and infiltration time 20-70 seconds after pouring $\mathrm{Al}$ melt into ceramic preform [10]. The maximum pressure (130 MPa) is maintained until the melt has solidified. With this procedure, the whole infiltration cycle does not take more than 120 s. [11] Pressure infiltration is useful technique for fast and high volume production of metal matrix composite systems having high liquid/solid surface tension and difficult wetting conditions.

Melt infiltration with and without pressure techniques are not always succesful for all combinations, Since aluminum alloy surface tension is a strong function of surface active elements and $\mathrm{Mg}$ content of the alloy, wetting and liquid penetration is improved by high pressure application on top of liquid aluminum during squeeze casting [12].

\section{Experimental Procedure}

In this work, melt infiltration method was used as major technique to produce high strength aluminum matrix composites. During these experiments, squeeze casting technique was used to achieve melt infiltration method with ceramic preforms. There are some reasons why squeeze casting process was preferred to form metal matrix composites. Wetting between ceramic preform and liquid $\mathrm{Al}$ melt can be increased by applying high pressure such as $150-170 \mathrm{MPa}$. It is a way of rapid process to produce aluminum matrix composite components. One of the most important advantages is that this casting technique is highly suited to mass production in the industry. This means that it is very economical process if it is aimed to produce great number of products. Furthermore, there is no shrinkage in squeeze casting process because of applied pressure during solidification. During squeeze casting process, the mould is heated up to $250^{\circ} \mathrm{C}$ in the beginning in order to prevent high heat flow from liquid metal to the metallic mould. At the same time, ceramic preforms were also heated up to $1000^{\circ} \mathrm{C}$ in the muffle furnace. After that, preform is placed into the mould cavity and hot metal is poured immediately. At the end, pressure was applied by squeeze casting technique yielding full penetration of liquid aluminum alloy. So composites were obtained after solidification. During these experiments, thermal paper on the lower punch was used in order to eliminate hot tears associated with differential thermal shrinkage. $\mathrm{Al}_{2} \mathrm{O}_{3}$ and $\mathrm{B}_{4} \mathrm{C}$ ceramic preforms were infiltrated with 7085 and 7075 aluminum alloys respectively (Figure 1).

\section{Results}

Aluminum 7075 matrix with $\mathrm{Al}_{2} \mathrm{O}_{3}, \mathrm{SiC}$ and $\mathrm{B}_{4} \mathrm{C}_{3}$ ceramic preforms were infiltrated with and without pressure. In the beginning, melt infiltration process was done by the first group of alumina preforms that were sintered at $1000,1100,1200$ and $1300^{\circ} \mathrm{C}$ whereas, only two of them were characterized. Metal matrix composites that were produces by the preforms (Figure 2).

After melt infiltration method, ceramic preform is confined by molten metal. In order to be able to investigate the microstructure and interfaces in between ceramic reinforcement and aluminum metal, these specimens were machines and metal matrix ceramic was revealed as it can be seen in below Figures 3 and 4 .

Boron Carbide - 7075 Aluminum composite structure after the production of alumina - 7085 aluminum matrix composites, the surfaces were prepared by metallographic methods. The microstructures of these composites were examined after processing to reveal interface microstructures.

Composites, produced by preform whose sintering temperatures are 1300 and $1450^{\circ} \mathrm{C}$. Obtaining high hardness values can be a promising property for the ballistic performance. High hardness values are needed in order to abrade the projectiles. As it was thought that the hardness of the tool steels is about $530 \mathrm{HB}$, the average composite hardness $545 \mathrm{HB}$ can be considered as sufficient results for ballistic armor plate material. Therefore, Alumina - 7085 aluminum composites can be a good candidate for these applications (Figure 5).

Even if there is incomplete penetration along the interfaces, melt infiltration was achieved successfully in most specimens since aluminum phases were detected in the pores of alumina structure as it can be seen in below figures. In other words, 7085 aluminum alloy was completely sucked by alumina preform with the help of squeeze casting. This shows that squeeze casting is a good method to produce metal matrix composites if ceramic preform is wetted and completely infiltrated (Figure 6).

In the beginning, ceramic plate was preheated at $500^{\circ} \mathrm{C}$ during 90 minutes. At the same time, mold was also heated up to $250^{\circ} \mathrm{C}$. Composite 
Citation: Kalkanlı A, Durmaz T, Kalemtaş A, Arslan G (2017) Melt Infiltration Casting of Alumina Silicon Carbide and Boron Carbide Reinforced Aluminum Matrix Composites. J Material Sci Eng 6: 357. doi: 10.4172/2169-0022.1000357

Page 3 of 5

\begin{tabular}{|c|c|c|c|}
\hline Materials & Density $\left(\mathbf{g} / \mathbf{c m}^{\mathbf{3}}\right)$ & Melting point $\left.\mathbf{~}^{\mathbf{}} \mathbf{C}\right)$ & Hardness (Knoop) \\
\hline $\mathrm{B} 4 \mathrm{C}$ & 2.52 & 2445 & 2750 \\
\hline $\mathrm{SiC}$ & 3.21 & 2730 & 2480 \\
\hline $\mathrm{Al}_{2} \mathrm{O}_{3}$ & 4.00 & 2070 & $2.9-3.7$ \\
\hline $\mathrm{Al}$ & 2.70 & 660 & 4.3 \\
\hline
\end{tabular}

Table 1: Some important properties of boron carbide, silicon carbide, alumina and aluminium.
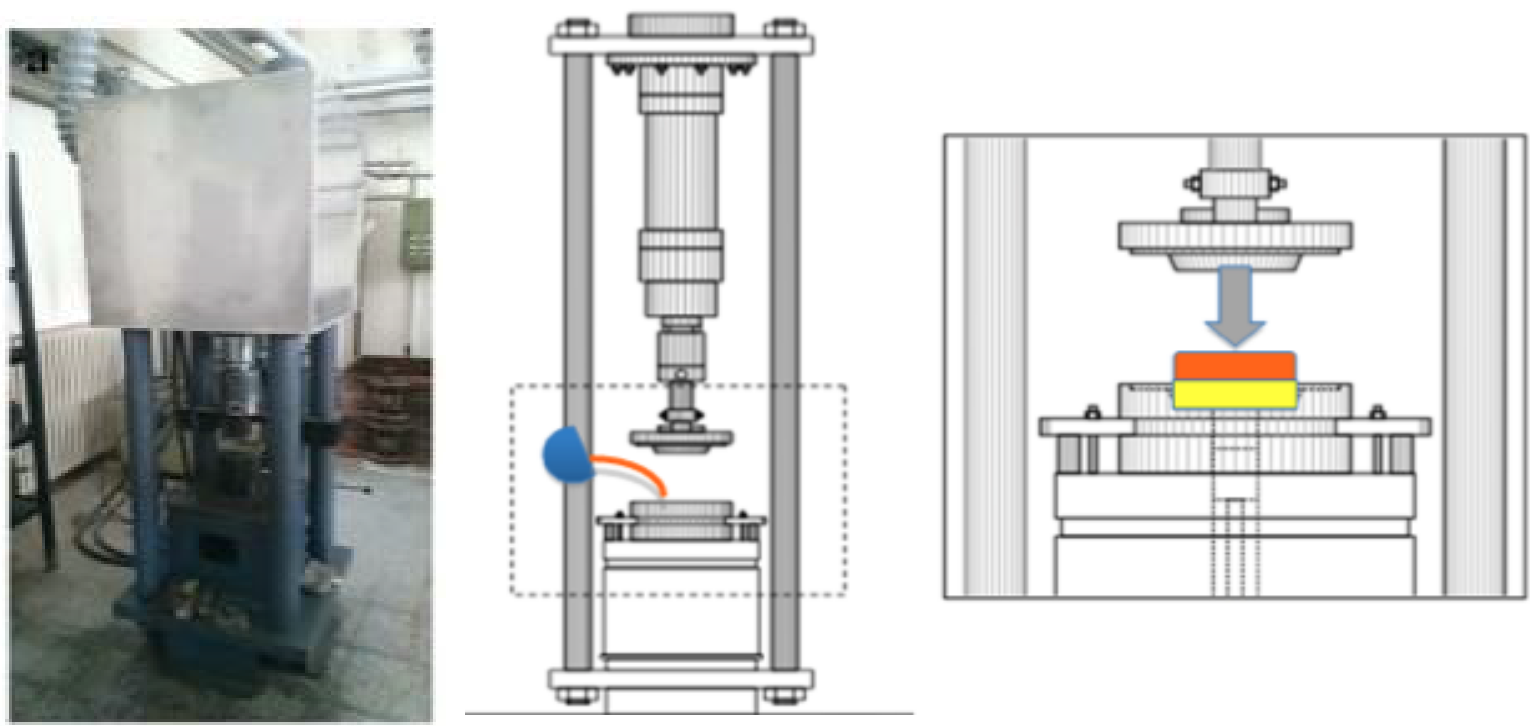

Figure 1: Actual and schematic view of metal infiltration process to produce metal composite.
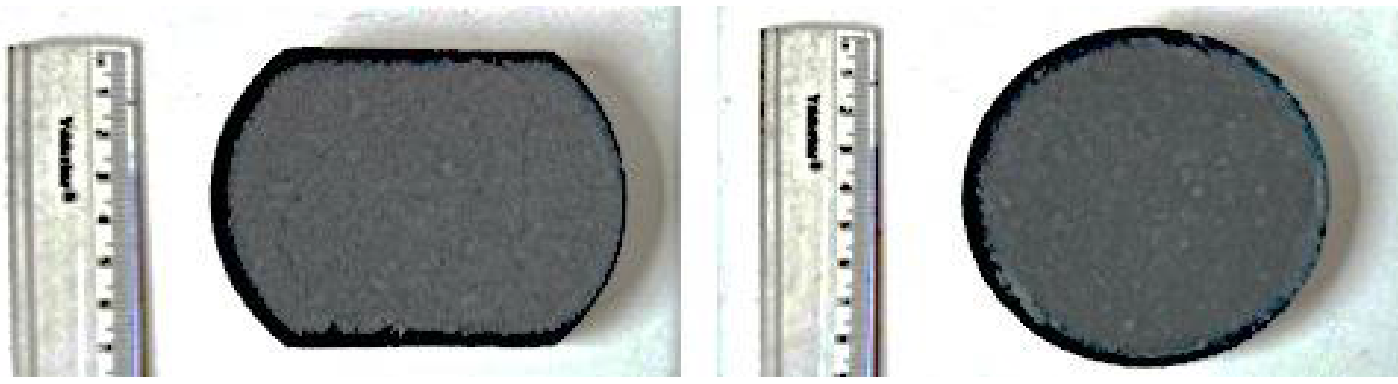

Figure 2: Aluminum infiltrated composites after sintering and infiltration processing.
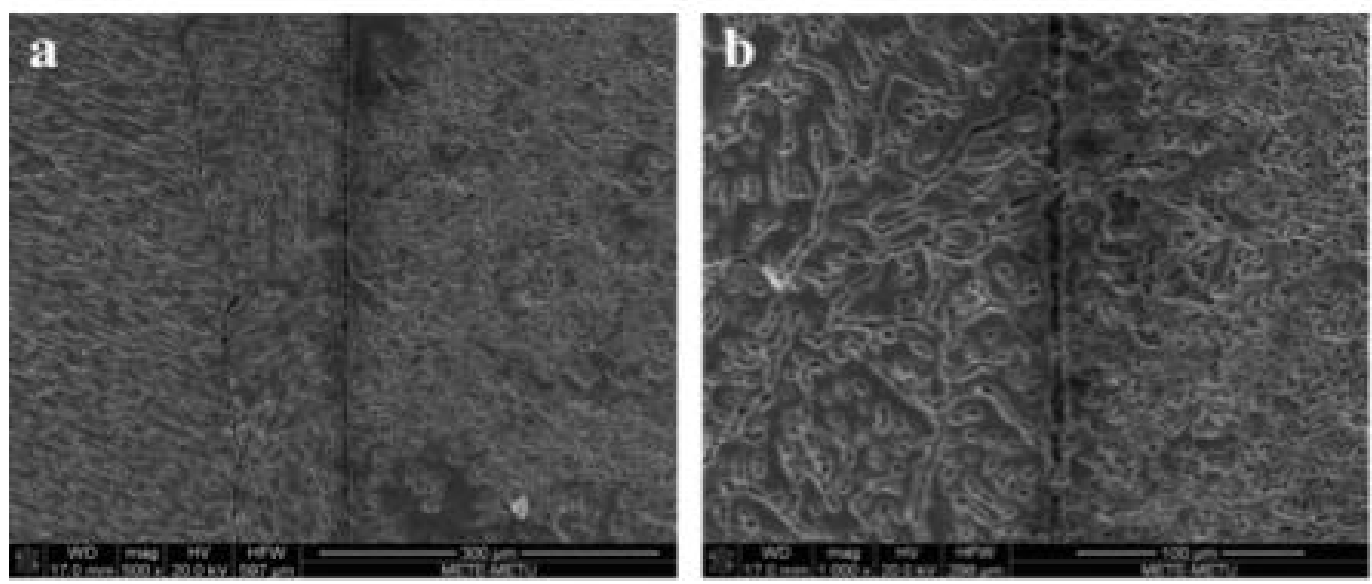

Figure 3: SEM images of the interface of alumina $/ 7085$ aluminum alloy composite sintered at $1300^{\circ} \mathrm{C}$ after infiltration. 

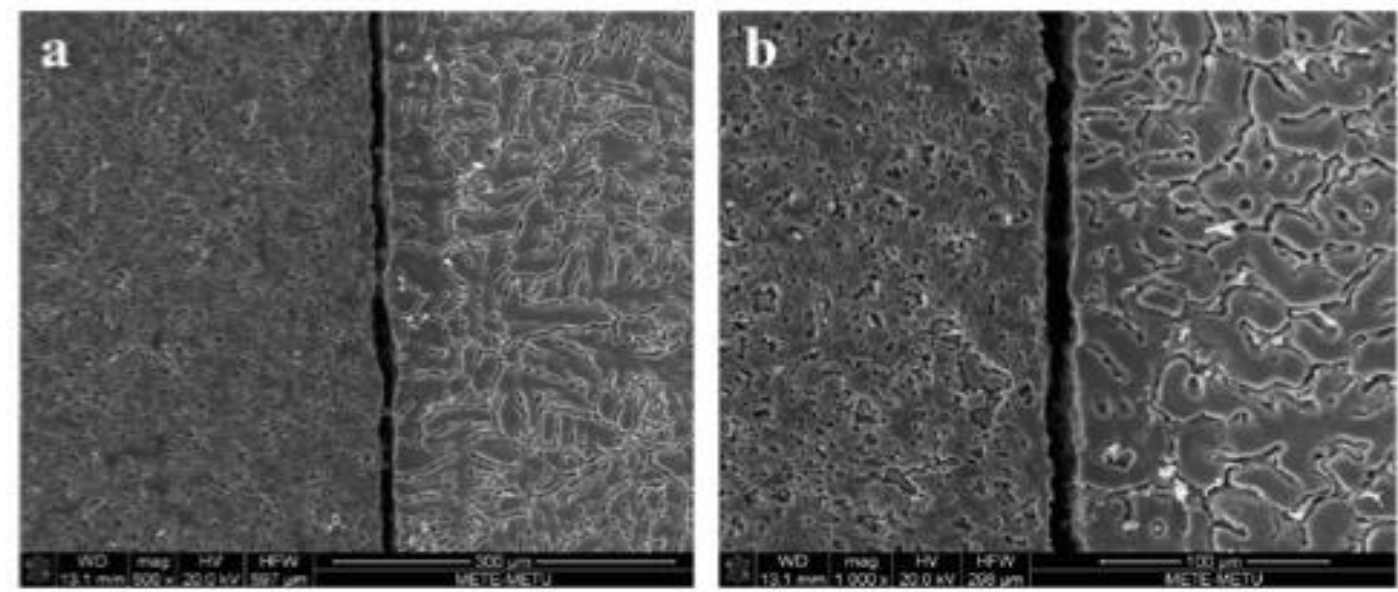

Figure 4: SEM images of the interface of alumina $/ 7085$ aluminum alloy composite sintered at $1450^{\circ} \mathrm{C}$ after infiltration revealed incomplete penetration of liquid aluminum alloy.

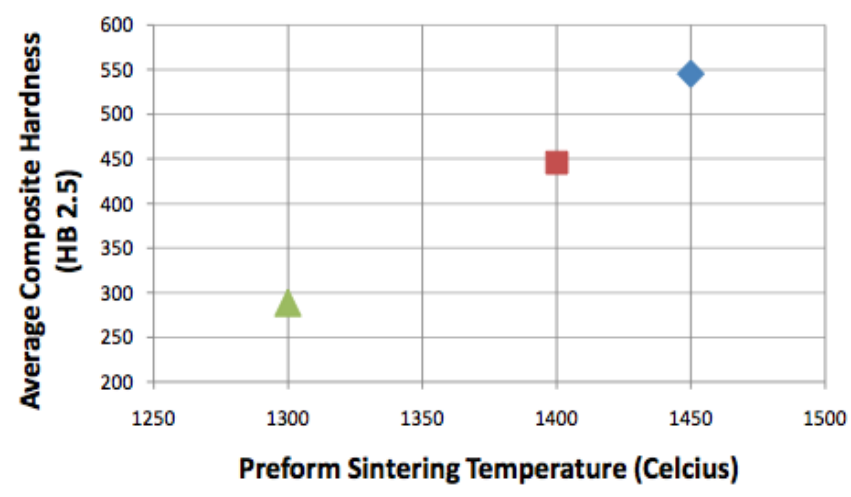

Figure 5: Distribution of composite hardness values according to $\mathrm{Al}_{2} \mathrm{O}_{3}$ preform sintering temperature.

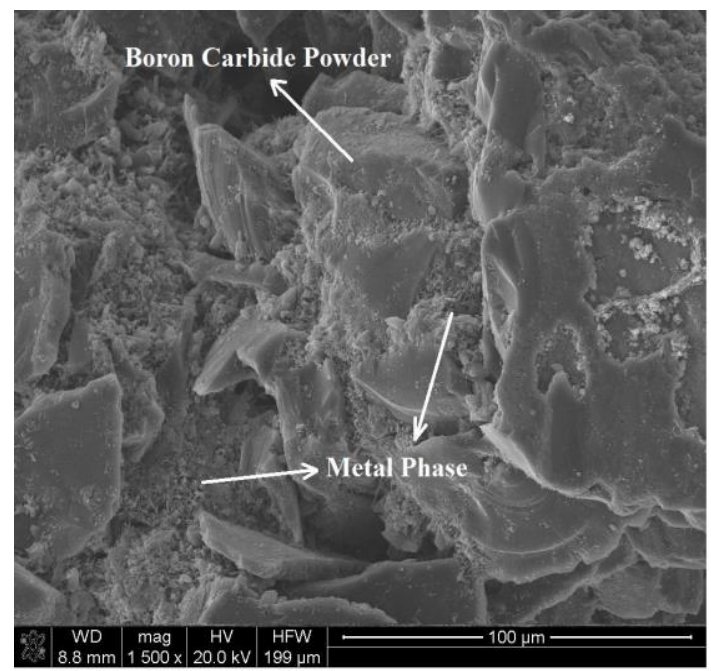

Figure 6: Microstructure of Boron Carbide - 7075 Aluminum composite.

plate was just put inside the mold and molten 7085 aluminum is poured into the cavity and squeeze casting was performed. At the end of this process crack formation was seen at the center of composite. Therefore, it should be noted that confinement operation is not possible by squeeze casting process for boron carbide/aluminum composite structures because of different thermal expansion coefficient, too fine carbide size and wetting difficulties for these materials (Figure 7).

Since heat treatments to achieve T6 condition is not convenient for infiltrated composites infiltrated ceramic preform and backing 7075 plate should be prepared separately, then two layers should be integrated in the end. Therefore plain 7075 squeeze cast plates without ceramic preforms were studied to determine the optimum solutionizing time and temperature for peak hardness condition of T6 heat treatment. It can be seen that $475^{\circ} \mathrm{C}$ is the best temperature for solution heat treatment of 7075 aluminum alloy according to the hardness values. The average hardness of the specimens that were solutionized at $475^{\circ} \mathrm{C}$ was measured as 178 $\mathrm{HB}$ and it was noted as the best hardness result after T6 heat treatment of squeeze casted 7075 aluminum alloy (Figure 8).

After the production of the boron carbide-7075 aluminum composites, confinement experiment was done for these composites. In this experiment, square shaped boron carbide-aluminum composite that was produced by melt infiltration without pressure. By confinement of infiltrated composites it was aimed to improve corrosion behavior of these composite structures. The main aim is to cover boron carbide composite with aluminum alloy.

High pressure die casting machine was used as an alternative way to study and develop high strength aluminum alloy as matrix alloy for defence and automotive applications. During the production, the speed of injection piston of high pressure die caster was decreased to $0.7 \mathrm{~m} / \mathrm{sec}$ and rheocasting was performed. Therefore, specimens were produced by rheocasting with high pressure die casting machine (Figure 9).

During this experiment, a special mold was used that give billets to machine tensile test specimens that were produced by rheocasting technique. Before machining, T6 heat treatments were operated for these specimens with the best conditions. These means that, $475^{\circ} \mathrm{C}$ was used as solutionizing temperature for 7075 aluminum alloy whereas, $465^{\circ} \mathrm{C}$ was used as solutionizing temperature for 7085 aluminum alloy. After that specimens were quenched in the water and they were aged at $120^{\circ} \mathrm{C}$ during 24 hours.

\section{Conclusions}

1. Both pressure and pressureless melt infiltration techniques yielded at least $85 \%$ ceramic phase containing composites. 


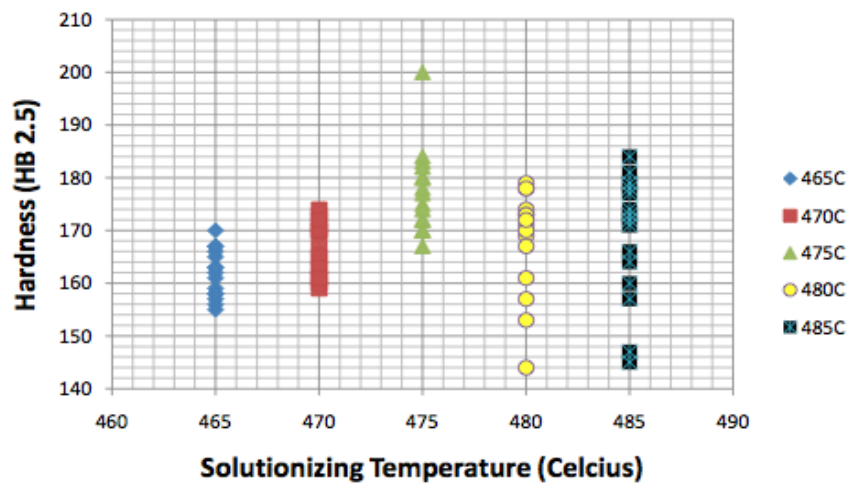

Figure 7: Hardness distribution of heat treated 7075 aluminum alloy for different solutionizing temperatures.

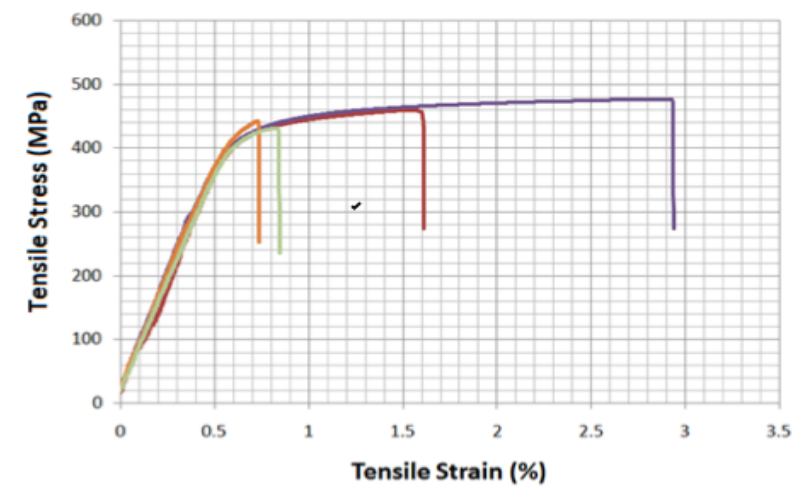

Figure 8: Tensile test results of 7075 aluminum alloy specimens, which are produced by rheocasting, after T6 heat treatment.
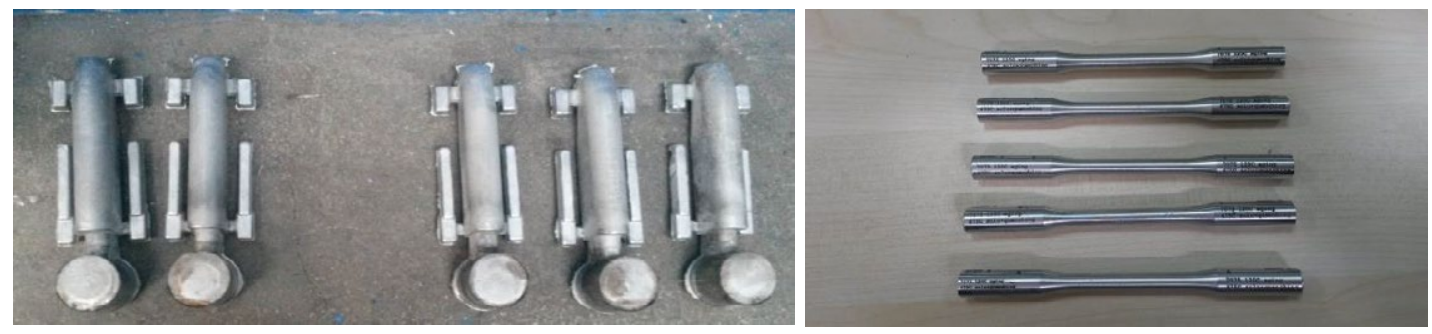

Figure 9: (a) Tensile test specimens obtained side by side 7075 aluminum alloy castings produced by rheocasting performed by HPDC, (b) machined tensile test specimens.

2. Pressureless infiltration of $\mathrm{B}_{4} \mathrm{C}$ preforms having $1-3 \mu \mathrm{m}$ carbide powder size produced for with 7075 alloy yielded complete infiltration. On contary pressure infitration of the same combination was failed due to low liquid phase penetration.

3. Pressure infiltration of $\mathrm{Al}_{2} \mathrm{O}_{3}$ preforms with coarse ceramic powders $20-50 \mu \mathrm{m}$ was completely infiltrated with 7075 alloy

4. To develop high strength backing alloy plate, rheocasting of 7075 alloy was performed and this process yielded $400-500$ $\mathrm{MPa}$ tensile strength after solutionizing at $475^{\circ} \mathrm{C}$ temperature for 90 mins then quenched in the water and aged at $120^{\circ} \mathrm{C}$ during $24 \mathrm{~h}$.

5. T6 Heat treatment of infiltated 7075 based composites is found to be unsuccesful due to large difference in thermal expansion coefficients of metallic and ceramic phases.

6. For integration of plain alloy backing plate and infiltared composites gluing with adhesive materials can be used

7. Highest composite hardness values $(550 \mathrm{HB})$ were obtained at ceramic $\left(\mathrm{Al}_{2} \mathrm{O}_{3}\right)$ preforms sintered at maximum sintering temperature of $1450^{\circ} \mathrm{C}$.

\section{References}

1. Balakrishnarajan MM, Pancharatna PD, Hoffmann R (2007) Structure and bonding in boron carbide: The invincibility of imperfections. New Journal of Chemistry 31: 473-485.

2. Arslan G, Kara F, Turan S (2003) Quantitative X-ray diffraction analysis of reactive infiltrated boron carbide-aluminium composites. Journal of the European Ceramic Society 23: 1243-1255

3. Dennis B, Rahbek B, Johnsen B (2015) Dynamic behaviour of ceramic armour systems, Norwegian Defence Research Establishment (FFI).
4. Roberson CJ, Hazell PJ (2003) Resistance of silicon carbide to penetration by a tungsten carbide cored projectile.

5. Arslan G, Kalemtas A (2009) Processing of silicon carbide-boron carbidealuminium composites. Journal of the European Ceramic Society 29: 473-480.

6. Nanda H, Appleby-Thomas GJ, Wood DC, Hazell PJ (2011) Ballistic behaviour of explosively shattered alumina and silicon carbide targets. Advances in Applied Ceramics 110: 287-292.

7. Mashhadi M, Taheri-Nassaj E, Sglavo VM, Sarpoolaky H, Ehsani N (2009) Effect of $\mathrm{Al}$ addition on pressureless sintering of B4C. Ceramics International 35: 831-837.

8. Kalkanlı A, Yılmaz S (2008) Synthesis and characterization of aluminum alloy 7075 reinforced with silicon carbide particulates. Materials \& Design 29: 775 780

9. Bilici İ, Metin GÜRÜ, Tekeli S (2015) Production of Ti-Fe Based MgAl2O4 Composite Material by Pressureless Infiltration Method. Gazi University Journal of Science 28: 295-299.

10. Halverson (1986) Boron-Carbide-Aluminum and Boron Carbide Reactive Cermets, United States Patent, Patent Number: 4, 605,440, Date of Patent: Aug. 12.

11. Lee HS, Hong SH (2003) Pressure infiltration casting process and thermophysical properties of high volume fraction SiCp/Al metal matrix composites. Materials Science and Technology 19: 1057-1064.

12. Chedru M, Vicens J, Chermant JL, Mordike BL (1999) Aluminium-aluminium nitride composites fabricated by melt infiltration under pressure. Journal of microscopy 196: 103-112. 